\title{
Investigation of the Relationship between Groundwater Level Fluctuation and Vegetation Cover by using NDVI for Shaqlawa Basin, Kurdistan Region - Iraq
}

\author{
Shwan Seeyan ${ }^{1,2}$, Broder Merkel $^{1} \&$ Rudy Abo ${ }^{1}$ \\ ${ }^{1}$ Hydrogeology Department, TU Bergakademie Freiberg, Gustav-Zeuner-Str. 12, 09599 Freiberg, Germany \\ ${ }^{2}$ Soil and Water Department, Salahaddin University-Erbil, Kurdistan Region, Iraq \\ Correspondence: Shwan Seeyan, Hydrogeology Department, TU Bergakademie Freiberg, Gustav-Zeuner-Str. 12, \\ Germany. Tel: 49-176-8455-6667. E-mail: shwanom2003@yahoo.com
}

\author{
Received: June 15, 2014 Accepted: July 14, 2014 Online Published: August 20, 2014 \\ doi:10.5539/jgg.v6n3p187 URL: http://dx.doi.org/10.5539/jgg.v6n3p187
}

\begin{abstract}
Groundwater as an important component of the hydrological cycle and it is the main resource for irrigation and domestic water supply particularly in arid and semi-arid area, where groundwater is a key feature that controls the distribution of vegetation. Distribution of vegetation was compared in the Shaqlawa Basin located in Kurdistan Region, Northern Iraq with the depth to groundwater by using the normalize difference vegetation index (NDVI) and the normalize different moisture index (NDMI). The NDVI and NDMI were derived from TM-5 images from 2006, 2007, 2009, 2010, and 2011. Depths to groundwater measurements were available from 11 monitoring wells. The results of statistical analysis show significant relationship between groundwater table and calculated vegetated areas at the $95 \%$ confidence levels with P-value less than 0.05 for all modeled years. The NDVI values at different depth to groundwater intervals indicate that higher vegetation coverage and more plant diversity exist in areas of shallow groundwater. Drought periods affected the groundwater table and less water infiltrating into soil, then the agricultural decreased. The scarcity of precipitation and other sources for fresh water increase the demand on groundwater water in agricultural activities in the region.
\end{abstract}

Keyword: groundwater depth, NDVI, NDMI, remote sensing, semi-arid area

\section{Introduction}

The water table is the boundary between the unsaturated and saturated zone. It represents the upper surface of the groundwater and it is the level at which the hydraulic pressure is equal to atmospheric pressure. The water level found in unused wells is often the same level as the natural water table (Shwani, 2008). Fluctuation is affected by many factors, such as rainfall intensity, rainfall quantity, the capability for water infiltration of rock and soil, groundwater depth above sea level, topography, evapotranspiration, and well discharge (Wilson, 1987). Climatic variations, precipitation, runoff, and evapotranspiration control groundwater table fluctuation, which alters both with seasons and from year to year; it is also affected by the withdrawal of excessive amounts of water from wells, or by their artificial recharge.

Water-level changes can be divided into short-term changes (daily fluctuation) and long-term changes that can be observed over months and years. Generally, fluctuations may happen due to three major factors: 1) changes in the volume of water stored in the aquifer (mainly controlled by recharge, leakage and abstraction); 2) changes in atmospheric pressure; and 3) changes caused by aquifer deformation.

Water level fluctuations are also caused by water wells producing groundwater in the vicinity of the observation wells. Many observation wells, especially those that were originally municipal water supply wells, show water-level changes.

Vegetation succession and cover patterns may be controlled by the groundwater table (Stromberg et al., 1996). In arid and semi-arid areas, soil moisture may be feed by groundwater through capillary forces. With shallower depth to groundwater, more soil moisture may be available, and vice versa (Rodriguez-Iturbe, 2000; Farmer et al., 2003; Pan et al., 2008). Thus, many plants take the groundwater as a source for growth especially in semi-arid regions, where groundwater supports a large density of vegetation by providing additional water for plant growth and 
transpiration (Naumburg et al., 2005; Wang et al., 2011).

The Normalized Difference Vegetation Index (NDVI) is an index obtained from reflectance measurements in the visible and near-infrared regions to analyze the relative vegetation awning (Deering, 1978). Quantitatively, assessment of vegetation growth may be determined by NDVI, where high vegetation coverage will have positive values, while soil and non-vegetation coverage will have less positive values. Living green vegetation absorbs solar radiation as a part of photosynthesis and plants reflect solar energy in the near infrared. This difference in absorption is unparalleled for living vegetation and determines the greenness of vegetation. NDVI is an index that measures this difference, providing a measure of vegetation density and condition. The fractional cover of the ground influences the NDVI by vegetation, vegetation density and vegetation greenness. It indicates the photosynthetic capacity of the land surface cover. NDVI can be calculated from the red reflectance and near-infrared reflectance. NDVI values affects by many factor like plant cover, biomass, photosynthetic activity of the vegetation, and soil moisture (Dubey et al., 2012). NDVI calculated from satellite data can be used to indicate beginning and stopping of greenness, rate of green-up and senescence, daily and seasonally growing (Olusegun \& Adeyewa, 2013).

A normal consequence of drought is a drop in crop production, due to inadequate and non-homogeneously distributed rainfall. The objective of this study was to investigate the relationship between vegetation and groundwater in the semi-arid Shaqlawa basin.

\section{Material and Method}

\subsection{Study Area}

The study area is located about $60 \mathrm{~km} \mathrm{NE}$ of Erbil city in northern Iraq and is surrounded by several mountains. The area is about $475 \mathrm{~km}^{2}$, extending between $\left(44^{\circ} 3^{\prime}-44^{\circ} 31^{\prime} \mathrm{E}\right)$ and $\left(36^{\circ} 35^{\prime}-36^{\circ} 19^{\prime} \mathrm{N}\right)$; the elevation ranges from 360 to 1500 meters above the sea level. The Shaqlawa basin lies within the high folded zone, according to Buday and Jassim (1987). The study area is bounded by the Greater Zab River from the northwest, the Safine Mountain from the southwest, the Shakrok Mountain from the northeast, and the Khalaen anticline in the southeast (Figure 1). Wheat, barley, vegetables, fruits (especially berries), lentils and chickpeas are the major crops in the study area.

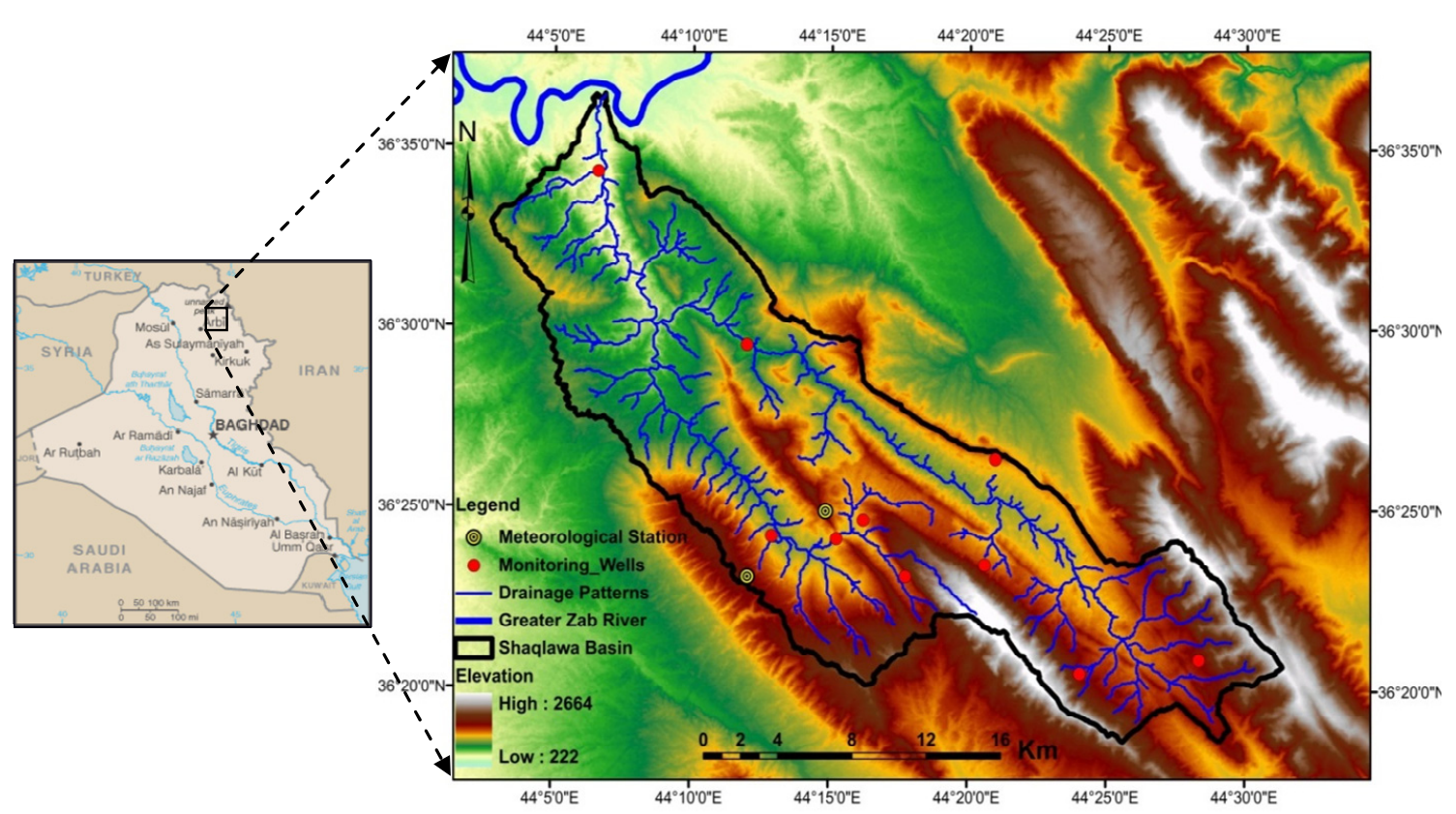

Figure 1. Map of Shaqlawa basin with digital terrain model, meteorological stations and observation wells

\subsection{Climate}

Meteorological data obtained from the Pirmam meteorological station for the period from 1992 to 2012, shows that annual precipitation is about $589 \mathrm{~mm}$, maximum and minimum mean monthly relative humidity is $71.7 \%$ in January and $33.9 \%$ in July respectively. Maximum monthly temperature is about $35.5{ }^{\circ} \mathrm{C}$ in July and the 
minimum is about $8.1{ }^{\circ} \mathrm{C}$ in January (Figure 2). Maximum evaporation is $266.7 \mathrm{~mm}$ in July and the minimum is $32.5 \mathrm{~mm}$ in January. The mean annual sunshine duration is 7.8 hours/day, and wind speed is between 1.9 and 2.9 $\mathrm{m} / \mathrm{sec}$ with an annual mean wind speed of $2.3 \mathrm{~m} / \mathrm{sec}$ (Appendix A).

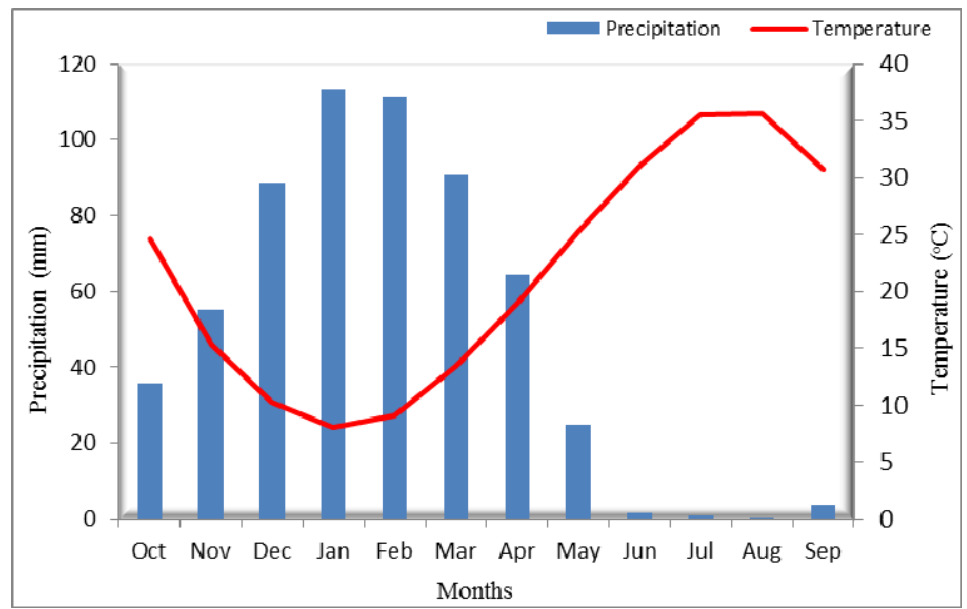

Figure 2. Mean monthly rainfall and temperature in Shaqlawa basin for the period between 1992-2012

\subsection{Aquifer Systems}

Three types of aquifer are represented in the study area: karst, fissured-karst and porous (inter-granular) aquifers. The karst aquifer, represented by the Bekhme formation, is a typical non-homogenous anisotropic aquifer containing groundwater reserves. These types of aquifers are characterized by their very high permeability and transmissivity values where groundwater flows through channels and cavities of different diameters depending on the degree of karstification development. In addition, drawdown values in wells that are drilled in such aquifers are very small. Most fresh water in the Shaqlawa basin is produced from this type of aquifer. The main characteristic of this aquifer is a turbulent water-flow regime. A high discharge capacity is often a feature of deep wells drilled in karstified rocks.

Fissured-karstic aquifers are represented by PilaSpi, Kolosh and Gercus formations containing medium to large groundwater reserves. These are also highly important for irrigation and water supply of cities. This type is developed in marly limestone, dolomitic limestone, limestone, and dolomite. The karstic-fissured aquifers are characterized by high permeability and transmissivity values (Stevanovic \& Markovic, 2004).

Inter-granular aquifers are represented by upper and lower Bakhtiari (Bai Hassan and Muqdadeya) formations, including overlying Pleistocene terrace and recent alluvium deposits. Typical characteristics of this aquifer are the repetition of fine, medium and coarse grained textures and variation in permeability from one site to another within the same aquifer horizon.

Other geological formations, such as lower and upper Fars (Fatha and Injana) and Kolosh formations, contain groundwater in limited and varying quantities. Impermeable layers, claystone or marls sometimes alternate with permeable rocks, such as limestone, which have low permeability and limited presence of groundwater. This rock complex represents either aquitards or even a full impermeable barrier to groundwater circulation (aquiclude).

There are four type of deposits in the study area: 1) Pliocene deposits (Lower and Upper Bakhtiari formations) represented by medium to high production, locally disconnected with impermeable claystone and semi-permeable siltstone, partly confined where covered by younger sediments; 2) Miocene deposits (Upper and Lower Fars formations) represented by low production, developed discontinuously in siltstone and sandstone intervals interchanged with almost impermeable claystone, with lower parts including gypsum and anhydrite layers; 3) Paleocene deposits (Kolosh, Gercus and PilaSpi formations), where Kolosh and Gercus are represented by fissured aquitard and low production aquifers in the case of conglomerate presence, and where PilaSpi is represented by medium to high production, including limestone, locally confined; and 4) Cretaceous deposits (Aqra-Bekhme, Qamchuqa and Sheranish formations), represented by karstic aquifers, medium to high production, well developed karstic features and a fissure system of privileged groundwater flow paths, with discharge through high yield springs or drilled deep wells (Figure 3). Geological map shown in Appendix B. 


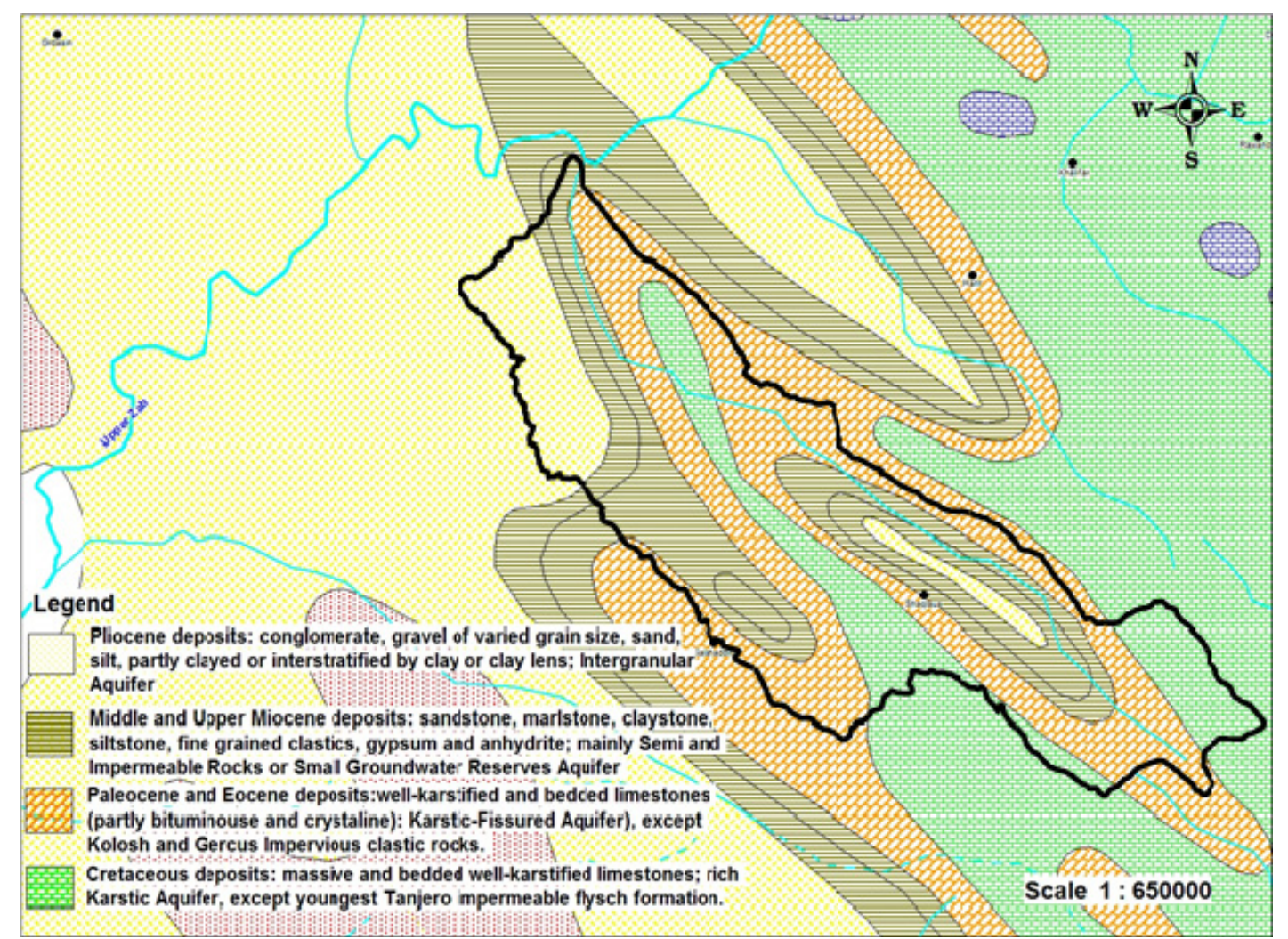

Figure 3. Hydrogeological map of northern Iraq shows type of aquifers and deposits in Shaqlawa basin (after Stevanovic \& Markovic, 2004)

Table 1. Satellite scenes (TM-5) with different dates

\begin{tabular}{ccc}
\hline Satellite Sense & Dates & Cloud Cover \\
\hline LT51690352006195MOR00 & 14 July 2006 & $10 \%$ \\
LT51690352006243MOR00 & 31 August 2006 & $0 \%$ \\
LT51690352006259MOR00 & 16 September 2006 & $0 \%$ \\
LT51690352006291MOR00 & 18 October 2006 & $0 \%$ \\
LT51690352007182MOR00 & 01 July 2007 & $0 \%$ \\
LT51690352007214MOR00 & 02 August 2007 & $0 \%$ \\
LT51690352007246MOR00 & 03 September 2007 & $0 \%$ \\
LT51690352007262MOR00 & 19 September 2007 & $0 \%$ \\
LT51690352009171MOR00 & 20 June 2009 & $10 \%$ \\
LT51690352009203MOR00 & 22 July 2009 & $0 \%$ \\
LT51690352009219MOR00 & 07 August 2009 & $0 \%$ \\
LT51690352009251MOR00 & 08 September 2009 & $0 \%$ \\
LT51690352010190MOR00 & 09 July 2010 & $0 \%$ \\
LT51690352010222MOR00 & 10 August 2010 & $0 \%$ \\
LT51690352010254MOR00 & 11 September 2010 & $0 \%$ \\
LT51690352011209MOR00 & 28 July 2011 & $0 \%$ \\
LT51690352011225MOR00 & 13 August 2011 & $0 \%$ \\
LT51690352011257MOR00 & 14 September 2011 & $0 \%$ \\
\hline
\end{tabular}

\subsection{Data}

\subsubsection{Satellite Images}

The multispectral images used in this study were scenes from Landsat TM-5 (path/row: 169/35), available for free download at the USGS global visualization viewer (www.glovis.usgs.gov). Eighteen scenes were acquired for June, July, August and September in 2006, 2007, 2009, 2010 and 2011 (Table 1). Cloud-free scenes were 
selected for all scenes (except two with 10\% cloud cover) in order to minimize uncertainties due to heterogeneous atmospheric conditions (Yuan \& Niu, 2008).

\subsubsection{Groundwater Table Fluctuation}

Groundwater data of 11 monitoring wells were provided by the Groundwater Directorate of the Ministry of Agriculture and Water Resource in the Erbil Governorate (Table 2). Monthly groundwater table data were used but the data are based on weekly readings. The data covers the timeframe between 2000 and 2012, however, satellite images without cloud cover (Landsat) were only available for 2006, 2007, 2009, 2010 and 2011 on www.glovis.usgs.gov. Well no. 11 was drilled into the confined aquifer, therefore, this well was an artesian well and we did not use the relationship between groundwater depth and NDVI area in this particular case.

Table 2. Coordinates (UTM, WGS 84), depth of the observation wells, depths to groundwater and elevations in meter

\begin{tabular}{ccccccccccc}
\hline Well No. & W-1 & W-2 & W-3 & W-4 & W-5 & W-6 & W-7 & W-8 & W-9 & W-10 \\
\hline Easting & 434565 & 433116 & 452650 & 436826 & 441108 & 441697 & 429625 & 446219 & 420329 & 428317 \\
Northing & 4029794 & 4028848 & 4022588 & 4026925 & 4027511 & 4032897 & 4029006 & 4021918 & 4047707 & 4038816 \\
Elevation & 855 & 804 & 759 & 982 & 982 & 888 & 757 & 1044 & 440 & 450 \\
Well Depth & 100 & 120 & 105 & 103 & 130 & 80 & 105 & 200 & 110 & 112 \\
Depth to GW & 14.8 & 5.5 & 16 & 14.42 & 22.4 & 25.7 & 28 & 15.6 & 16.3 & 17.2 \\
\hline
\end{tabular}

\subsection{NDVI and NDMI}

Vegetation density responds to the plant water content. The NDVI derived from digital satellite data corresponds to the density of green vegetation (Gao, 1996; Chen \& Brutsaert, 1998; Boone et al., 2000). The NDVI is a measure of vegetation density calculated from multispectral data. The magnitude of NDVI is related to the level of photosynthetic activity in the observed vegetation (Kidwell, 1990). It is calculated based on the ratio between the near-infrared band and the red band:

$$
N D V I=(\rho 4-\rho 3) /(\rho 4+\rho 3)
$$

Where $\rho 4$ is the near-infrared spectral band and $\rho 3$ is the visible red spectral band. Areas with a high vegetation index represent intensive vegetation due to their high reflectance of NIR compared to VIS. The groundwater depth to NDVI relationship has been investigated to observe any potential effects of vegetation on shallow groundwater.

The Normalized Difference Moisture Index (NDMI) was derived from Landsat spectral bands 4 and 5 and calculated using the following equation:

$$
N D M I=(\rho 4-\rho 5) /(\rho 4+\rho 5)
$$

This index contrasts the near-infrared (NIR) band 4 , which is sensitive to the reflectance of leaf chlorophyll content to the mid-infrared (MIR) band 5, which is sensitive to the absorbance of leaf moisture.

NDMI evaluates the different content of humidity from the landscape elements, especially for soils, rocks and vegetation and it is excellent indicator for dryness.

\section{Results and Discussion}

\subsection{Vegetation and Groundwater Relationship}

The change of depth to groundwater is related to atmospheric and surface conditions, such as precipitation, temperature, soil adoption, vegetation water content, soil humidity and evaporation (Liang et al., 1994; Mitchell \& DeWalle, 1998; Wooldridge \& Kalma, 2001). Groundwater fluctuation analysis estimated the variations in stored water, renewable storage water quantity, and the investment of groundwater (Lioyd, 1999). Aquifer storage changes affect the groundwater level fluctuation, which includes the addition or extraction of water from the aquifer through natural means or human activities. In the Shaqlawa basin, depth to groundwater increases during the dry seasons because discharge is greater than recharge, while in wet seasons, groundwater depth decreases (rising groundwater level) because the quantity of recharge is greater than the discharge. Because of drought periods in 2008, 2009 and 2010, the groundwater depth was deeper than that in 2006 and 2007 (Figure 4). During the dry months, evapotranspiration increases, precipitation and groundwater recharge will decreases; therefore, fresh water capacity in the soil is reduced and may lead to associated drought stress and limited growth (Aguilar, et al., 2012). 

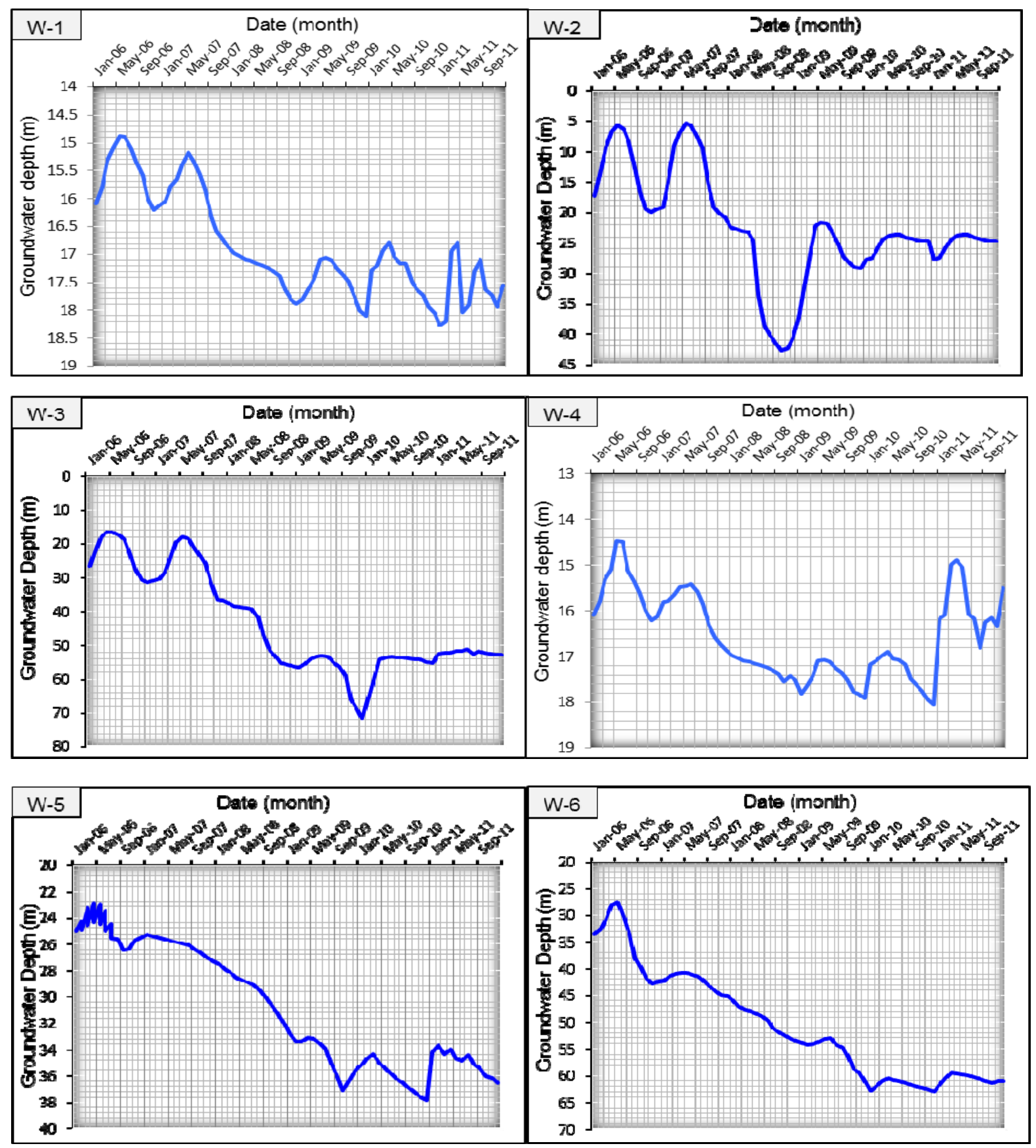

Figure 4. Groundwater level changes during 2006-2011 for different wells: depths to groundwater increase in dry season and rise in wet season, in the drought period the water level was deeper than in other periods (Continue..) 

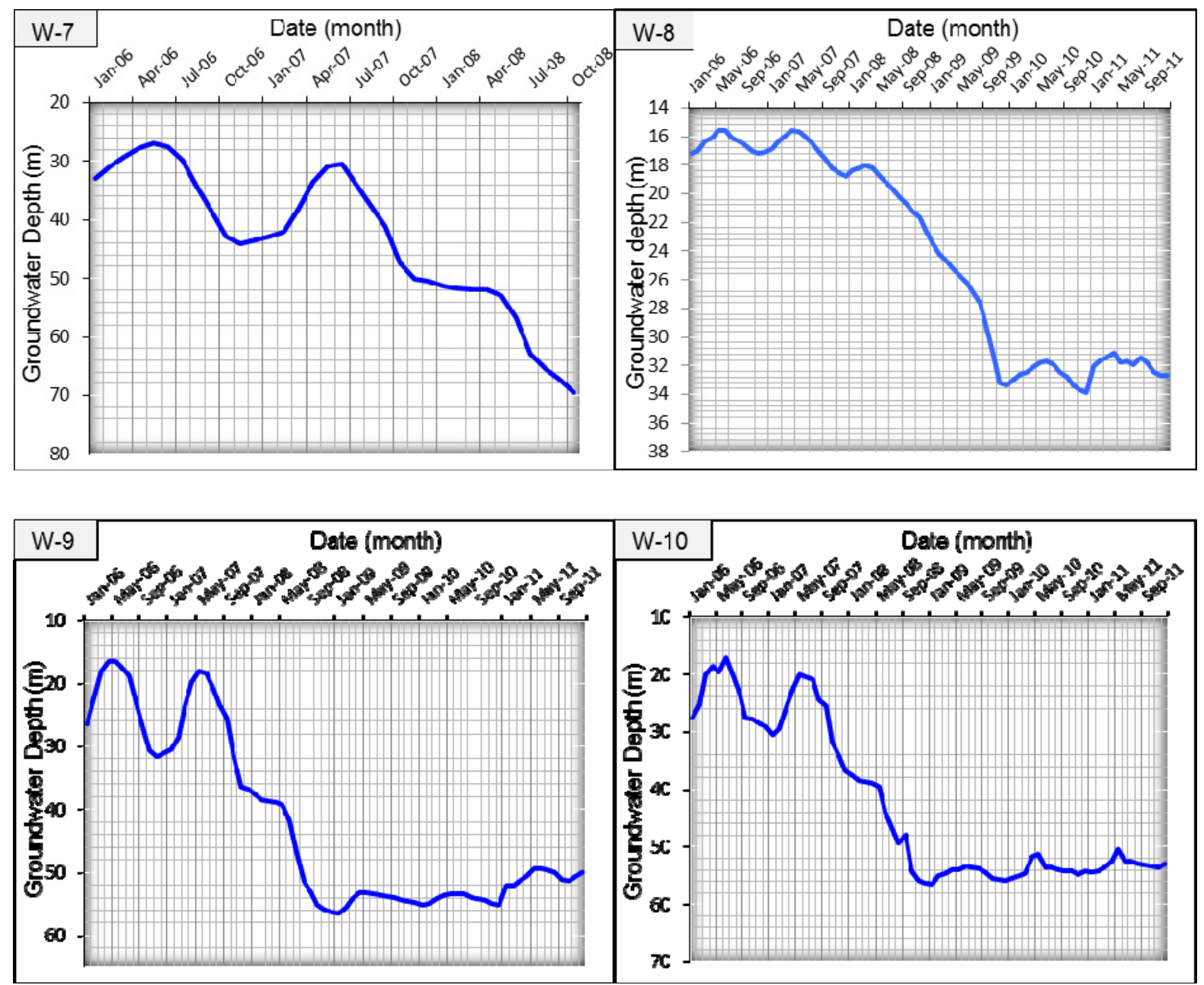

Figure 4. Groundwater level changes during 2006-2011 for different wells: depths to groundwater increase in dry season and rise in wet season, in the drought period the water level was deeper than in other periods

The correlation coefficient between groundwater depth and NDVI indicates a relationship between the variables. P-values are less than 0.05 which means a statistically significant relationship between depth to groundwater and NDVI area (Figure 5). The NDVI area represents the area which covered by vegetation in $\mathrm{km}^{2}$. Well no. 7 (W-7) did not fit with the remote sensing data because of missing values (Table 3).

There is an indirect relationship between NDVI and depth to water, in which vegetation area increases as depth to groundwater decreases (rising water table), and vice versa.

Table 3. Statistical analysis for the observation wells in the study area by using SPSS program

\begin{tabular}{ccccccccccc}
\hline Well No. & W-1 & W-2 & W-3 & W-4 & W-5 & W-6 & W-7 & W-8 & W-9 & W-10 \\
\hline$r$ & -0.773 & -0.874 & 0.836 & 0.799 & 0.82 & 0.613 & n.f & 0.785 & 0.801 & 0.611 \\
$P$-value & 0.0007 & 0.0000 & 0.0004 & 0.0001 & 0.0002 & 0.0152 & n.f & 0.0001 & 0.0003 & 0.0119 \\
\hline
\end{tabular}

Note: The value with n.f is mean not fitted with model. (r) is correlation coefficient. 


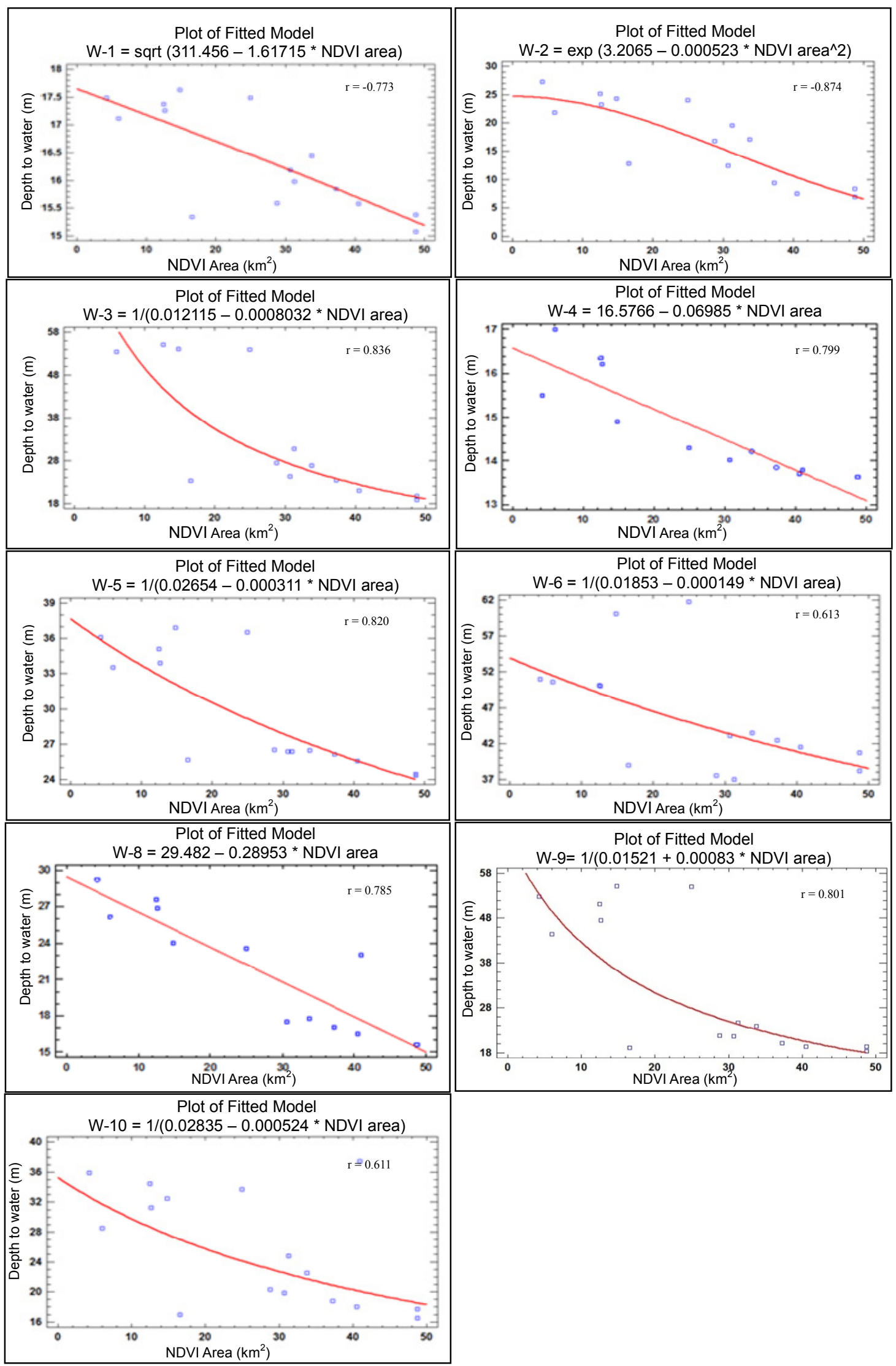

Figure 5. Relationship between groundwater depth and NDVI area for the observation wells except W-7 which is not fitted with the model. Simple regression line was used by SPSS program to plot the relationship 


\subsection{Relationship between Soil Moisture and Vegetation Cover}

Satellite soil moisture has been widely used in agricultural, hydrological, and ecological studies due to its spatial coverage and temporal continuity (Lakshmi, 2013). Soil wetness index represents the amount of water in the top few centimeters of the soil.

There is a significant correlation between the NDMI and the wetness index (Jin \& Sader, 2005). The NDMI index was first proposed by Gao (1996), who demonstrated that it is sensitive to changes in water content in vegetation canopies.

Monitoring of harvesting and other disturbances has proven that NDMI is a promising technique (Wilson \& Sader, 2002). The NDMI is calculated based on the contrast between mid-infrared (MIR) and near-infrared (NIR) reflectance, which are sensitive to changes in vegetation leaf structure and water content (Hayes \& Cohen, 2007; Hayes et al., 2008). The area of NDVI and NDMI was calculated by geometrical calculation and statistical tools in ArcGIS version 10, NDVI has a direct relationship with NDMI because the area of NDVI increases with increasing NDMI area (Table 4).

Table 4. NDMI and NDVI areas in $\mathrm{km}^{2}$ for different periods in Shaqlawa-basin by using ArcGIS

\begin{tabular}{ccccccc}
\hline Date & July_2006 & Aug_2006 & Sep_2006 & Oct_2006 & July_2007 & Aug_2007 \\
\hline NDMI area & 4.417 & 1.442 & 3.241 & 5.579 & 1.562 & 5.580 \\
NDVI area & 48.701 & 16.576 & 28.808 & 31.241 & 40.495 & 37.271 \\
& 3_Sep_2007 & 19_Sep_2007 & June_2009 & July_2009 & Aug_2009 & Sep_2009 \\
& 3.745 & 4.811 & 0.014 & 0.528 & 0.227 & 0.014 \\
& 30.722 & 33.735 & 6.021 & 12.647 & 12.525 & 4.283 \\
& July_2010 & Aug_2010 & Sep_2010 & July_2011 & Aug_2011 & Sep_2011 \\
& 2.819 & 1.656 & 0.697 & 1.578 & 2.45 & 1.467 \\
& 40.918 & 24.928 & 14.845 & 23.7 & 37.5 & 22.2 \\
\hline
\end{tabular}

* NDMI area represents the moisture area in Shaqlawa basin. NDVI area represents the vegetation cover area.

\subsection{Draught, Vegetation and Moisture Indices}

During the wet season, substantial vegetation in the investigated area was often associated with shallow groundwater levels, whereas in the dry season, water table and vegetation cover decreased. Drought conditions caused losses in agricultural productivity and affected the environment through vegetation loss, soil erosion and a decrease of the groundwater table. During the drought period no recharge occurs, and because of an increase in the pumping of water from the wells for different purposes including drinking purposes, animal consumption, irrigation, and other agriculture uses, such as cultivation of wheat, barley, fruits (especially berries, grapes and pomegranates), lentils and chickpeas, hence, groundwater table decreases.

The agricultural land in the Shaqlawa area is fertile; agriculture and irrigation depend on rain and normal water wells, therefore, the drought affected on the agricultural production.

Vegetation biomass and yield can be evaluated from space using vegetation indices, (e.g. satellite sensors could be examined for the plants which absorb the accumulative photosynthetic active radiation) (Bastiaanssen \& Ali, 2003). The remote sensing data which were collected by Landsat TM-5 shows an effective method for monitoring the vegetation cover of the Shaqlawa basin, where the wavelength of red and near infrared bands presented high sensitivity to the changing of vegetation indices.

Vegetation cover was much denser in places where the groundwater table was shallow, which the relation between groundwater depth and vegetation cover shows shallow groundwater depth with high density of vegetation, the NDVI value in the Shaqlawa basin ranged from -0.25 to +0.65 (Figure 6, Appendix 1C).

The NDMI also increasing with decreasing in the depth to groundwater, because soil moisture controls the partitioning of rainfall into runoff and infiltration. In the study area, NDMI ranged from -0.37 to +0.86 (Figure 7 , Appendix $2 \mathrm{C}$ ). The values higher than 0.1 are represent high humidity level, and low values (close to -1 ) represent low humidity level. High values of NDVI and NDMI were found in mountain area and the low values in the plain area. 


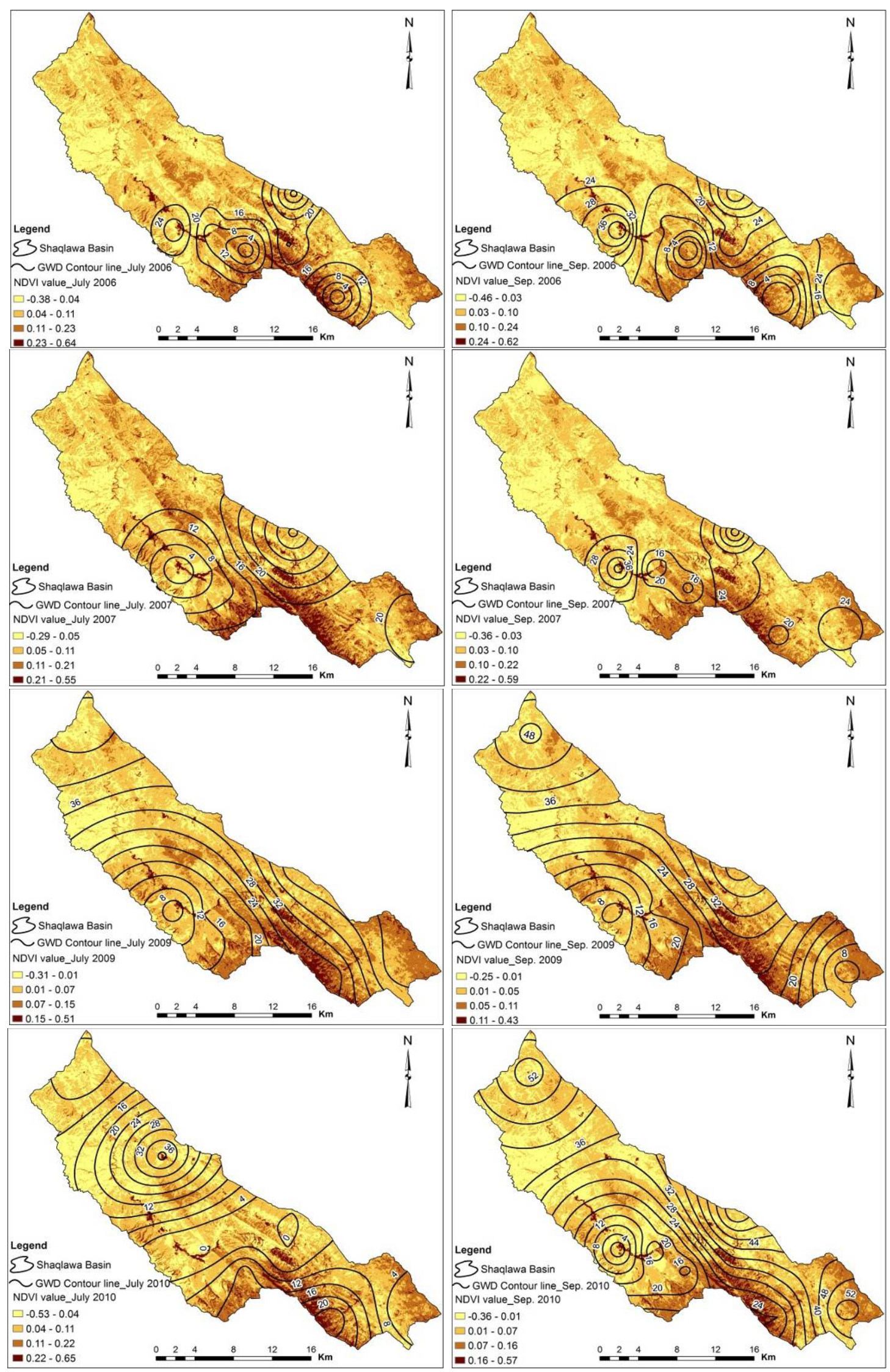

Figure 6. Depths to groundwater contour lines with NDVI value for Shaqlawa basin during different periods, contour interval is 4 meter 


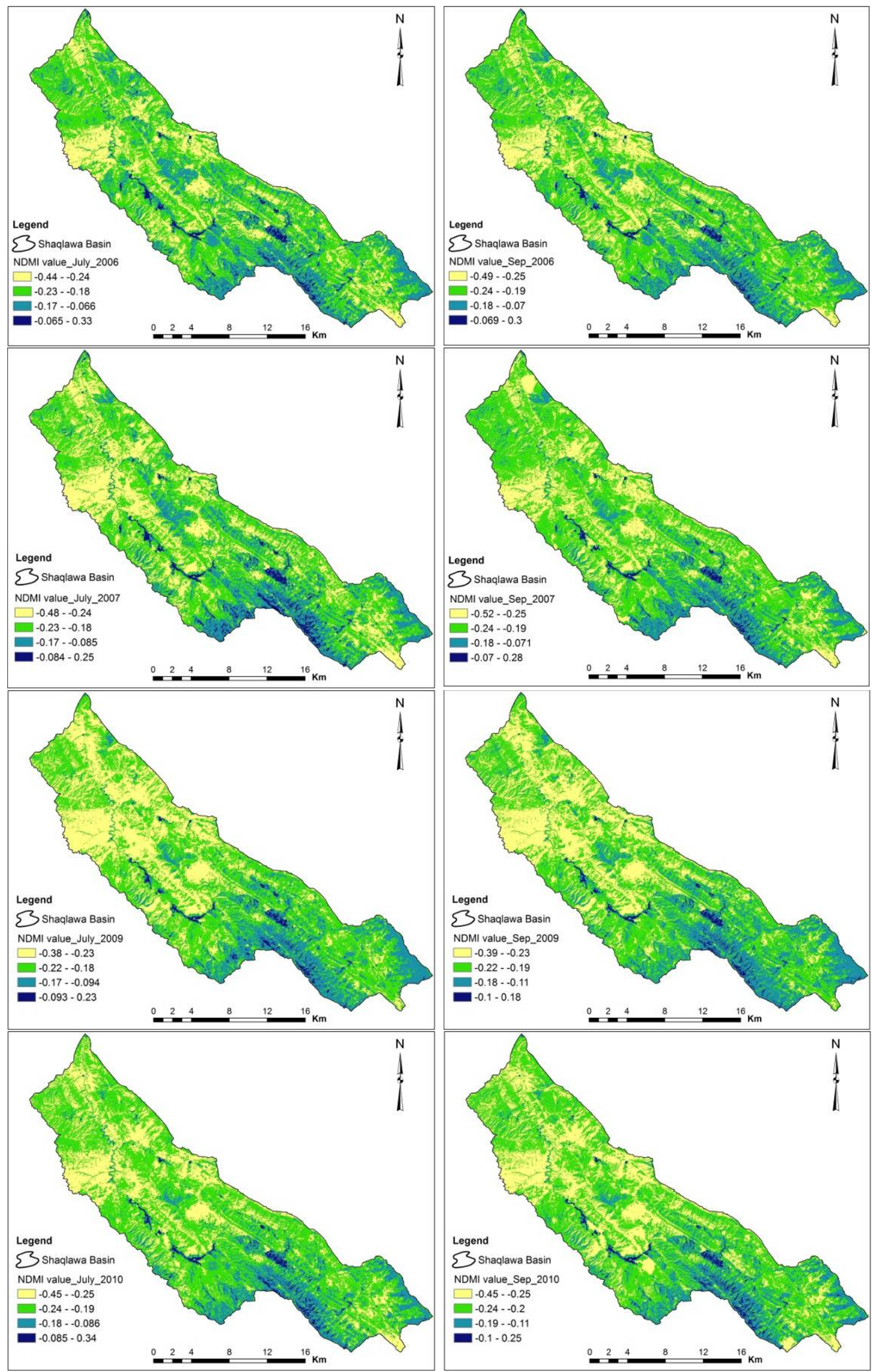

Figure 7. NDMI values for Shaqlawa basin during different periods 


\section{Conclusions}

This study detected the ability of remotely sensed satellite derived NDVI in the monitoring of greenness of vegetation, and NDMI from the leaf chlorophyll and moisture in Shaqlawa Basin. Shaqlawa district represents one of the largest areas for tourism; therefore water is used for social-economic development, and using large amount of groundwater for different consumption make the groundwater depth increased. The existence of vegetation and soil moisture in the area affects on the groundwater table because soil moisture and vegetation cover controls the partitioning of rainfall into runoff distribution and infiltration. Deep groundwater depths cause a shortage of water for the root system; therefore it is not able to supply adequate water for the canopies.

In Kurdistan region the groundwater table fluctuations measurement started in year 2000. In this study, groundwater table data from 2006 was used for determination the relationship between water table fluctuation and NDVI, because there are no satellite scenes available in USGS site for the years 2001 until 2006 and 2008. This study is the first application of groundwater table fluctuation study and NDVI relationship in Kurdistan Region, thus this study is important for this area.

Based on a combination of remote sensing and groundwater observation data, the relationship between groundwater depth and vegetation cover in the study area was determined; there was high vegetation cover in the south and south-eastern part of the Shaqlawa basin which is represented the mountain areas because of the large amount of precipitation and infiltration capacity as well as the variation in humidity, and low vegetation cover in the north and north-western part of the basin.

\section{Acknowledgment}

The authors would like to thank the Ministry of Agriculture and Water Resources-Kurdistan Regional Government/Iraq and USGS for making data available for this study.

\section{References}

Aguilar, C., Zinnert, J., Polo, M., \& Young, D. (2012). NDVI as an indicator for changes in water availability to $\begin{array}{lllll}\text { woody } & \text { vegetation. } & \text { Ecological }\end{array}$ http://dx.doi.org/10.1016/j.ecolind.2012.04.008

Bastiaanssen, W. G. M., \& Ali, S. (2003). A new crop yield forecasting model based on satellite measurements applied across the Indus basin, Pakistan. Agricultural Ecosystem Environment, 94(3), 321-340. http://dx.doi.org/10.1016/S0167-8809(02)00034-8

Boone, R. B., Galvin, K. A., Smith, N. M., \& Lynn, S. J. (2000). Generalizing El Nino effects upon Maasai livestock using hierarchical clusters of vegetation patterns. Photogrammetric Engineering \& Remote Sensing, 66(6)(Remote Sensing), 737-744.

Buday, T., \& Jassim, S. (1987). The Regional Geology of Iraq (Stratigraphy and Paleogeography) (p. 352).

Chen, D. Y., \& Brutsaert, W. (1998). Satellite-sensed distribution and spatial patterns of vegetation parameters over a tallgrass prairie. Journal of the Atmospheric Sciences, 55, 1225-1238. http://dx.doi.org/10.1175/1520-0469(1998)055<1225:SSDASP $>2.0 . C O ; 2$

Deering, D. W. (1978). Rangeland reflectance characteristics measured by aircraft and spacecraft sensor. Texas A\&M University.

Dubey, S. K., Pranuthi, G., \& Tripathi, S. K. (2012). Assessing the Relation Between NDVI and Rainfall over India. International Journal of Water Resources and Arid Environments, 2(4), 108-114.

Farmer, D., Slvapalan, M., \& Jothltyangkoon, C. (2003). Climate, soil, and vegetation controls upon the variability of water balance in temperature and semiarid landscapes: Downward approach to water balance analysis. Water Resources Research, 39(2), 1035-1056. http://dx.doi.org/10.1029/2001WR000328

Gao, B. (1996). NDWI-A normalized difference water index for remote sensing of vegetation liquid water from space. Remote Sensing of Environment, 58, 257-266. http://dx.doi.org/10.1016/S0034-4257(96)00067-3

Hayes, D., \& Cohen, W. (2007). Spatial, spectral and temporal patterns of tropical forest cover change as observed with multiple scales of optical satellite data. Remote Sensing of Environment, 106, 1-16. http://dx.doi.org/10.1016/j.rse.2006.07.002

Hayes, D., Cohen, W., Sader, S., \& Irwin, D. (2008). Estimating proportional change in forest cover as a continous variable from multi-layer MODIS data. Remote Sensing of Environment, 112, 735-749. http://dx.doi.org/10.1016/j.rse.2007.06.003 
Jin, S., \& Sader, S. A. (2005). MODIS time-series imagery for forest disturbance detection and quantification of patch size effects. Remote Sensing of Environment, 99(4), 462-470. http://dx.doi.org /10.1016/j.rse.2005.09.017

Kidwell, K. B. (1990). Gobal vegetation index user's guide. U.S. Department of Commerce / NOAA/NESDIS / NCDC / Satellite. Data Services Divison (p. 85).

Lakshmi, V. (2013). Remote Sensing of Soil Moisture. ISRN Soil Science, 2013(424178), 33.

Liang, X., Lettenmaier, D. P., Wood, E. F. \& Burges, S. J. (1994). A simple hydrologically based model of land surface water and energy fluxes for general circulation models. Journal of Geophysical Research: Atmospheres, 99(D7), 14415-14428. http://dx.doi.org/10.1029/94JD00483

Lioyd, J. W. (1999). Water Resources of Hard Rock Aquifers in arid and Semi-Arid Zones (p. 184).

Mitchell, K. M., \& DeWalle, D. R. (1998). Application of the snowmelt runoff model using multiple-parameter landscape zones on the Towanda Creek basin, Pennsylvania1. JAWRA Journal of the American Water Resources Association, 34(2), 335-346. http://dx.doi.org/10.1111/j.1752-1688.1998.tb04139.x

Naumburg, E., Mata-gonzalez, R., Hunter, R., Mclendon, T. \& Martin, D. (2005). Phreatophytic Vegetation and Groundwater Fluctuations: A Review of Current Research and Application of Ecosystem Response Modeling with an Emphasis on Great Basin Vegetation. Environmental Management, 35(6), 726-740. http://dx.doi.org/10.1007/s00267-004-0194-7

Olusegun, C., \& Adeyewa, Z. (2013). Spatial and Temporal Variation of Normalized Difference Vegetation Index (NDVI) and Rainfall in the North East Arid Zone of Nigeria. Atmospheric and Climate Sciences, 3(4), 421-426. http://dx.doi.org/10.4236/acs.2013.34043

Pan, Y. X., Wang, X. P., Jia, R. L., Chen, Y. W., \& He, M. Z. (2008). Spatial variability of surface soil moisture content in a re-vegetated desert area in Shapotou, northern China. Journal of Arid Environment, 72(9)(Environment), 1675-1683. http://dx.doi.org/10.1016/j.jaridenv.2008.03.010

Rodriguez-Iturbe, I. (2000). Ecohydrology: A hydrologic perspective of climate-soil-vegetation dynamies. Water Resources Research, 36(1), 3-9. http://dx.doi.org/10.1029/1999WR900210

Shwani, S. O. (2008). Hydrogeology and Hydrochemistry of Bashtapa Sub-Basin in Erbil Governorate Kurdistan Region - Iraq. Salahaddin University.

Stevanovic, Z., \& Markovic, M. (2004). Hydrogeology of Northern Iraq, General hydrogelogy and aquifer system (Volum 2, p.,264).

Stromberg, J. C., Tiller, R. \& Richter, B. (1996). Effects of Groundwater Decline on Riparian Vegetation of Semiarid Regions: The San Pedro, Arizona. Ecological Society of America, 6(Ecological Application), 113-131. http://dx.doi.org/10.2307/2269558

Wang, P., Zhang, Y., Yu, J., Fu, G., \& Ao, F. (2011). Vegetation dynamics induced by groundwater fluctuations in the lower Heihe River Basin, northwestern China. Journal of Plant Ecology, 4(1-2), 77-90. http://dx.doi.org/10.1093/jpe/rtr002

Wilson, E. M. (1987). Engineering Hydrology (3rd ed., p. 309).

Wilson, E., \& Sader, S. (2002). Detection of forest harvest type using multiple dates of Landsat TM imagery. Remote Sensing of Environment, 80, 385-398. http://dx.doi.org/10.1016/S0034-4257(01)00318-2

Wooldridge, S. A., \& Kalma, J. D. (2001). Regional-scale hydrological modeling using multiple-parameter landscape zones and a quasi-distributed water balance model. Hydrology and Earth Sciences, 5(1), 59-74. http://dx.doi.org/10.5194/hess-5-59-2001

Yuan, J., \& Niu, Z. (2008). Evaluation of atmospheric correction using FLAASH. Earth Observation and Remote Sensing Applications, 2008. EORSA 2008. International Workshop on. http://dx.doi.org/10.1109/EORSA.2008.4620341 


\section{Appendix A}

\section{Climatic parameter}

Table 1A. Mean monthly climatic parameter of Shaqlawa basin for the period 1992-2012, Pirmam meteorological station

\begin{tabular}{ccccccccccccc}
\hline Month & Jan & Feb & Mar & Apr & May & Jun & Jul & Aug & Sep & Oct & Nov & Dec \\
\hline Rainfall $(\mathrm{mm})$ & 113.3 & 111.1 & 90.6 & 64.2 & 24.8 & 1.5 & 0.8 & 0.02 & 3.7 & 35.7 & 55.1 & 88.6 \\
R.H \% & 71.7 & 70.9 & 59.6 & 57.7 & 43.9 & 34.3 & 33.9 & 34.9 & 38.6 & 49.1 & 59.1 & 64.4 \\
Temperature $\left({ }^{\circ} \mathrm{C}\right)$ & 8.1 & 9.1 & 13.5 & 18.9 & 25.4 & 31.13 & 35.5 & 35.5 & 30.8 & 24.7 & 15.3 & 10.3 \\
Sunshine (h/d) & 4.6 & 4.9 & 6.2 & 6.6 & 8.98 & 11.5 & 11.7 & 10.7 & 9.9 & 7.6 & 6.2 & 5.1 \\
Wind Speed (m/s) & 2.0 & 2.4 & 2.8 & 2.9 & 2.6 & 2.7 & 2.4 & 2.3 & 2.1 & 2.2 & 1.9 & 1.9 \\
Evaporation(mm) & 32.5 & 38.4 & 94.2 & 116.1 & 188.9 & 253.9 & 266.7 & 258.8 & 180.7 & 122.7 & 53.4 & 43.0 \\
\hline
\end{tabular}

* R.H : relative humidity.

\section{Appendix B}

\section{Geological Map}

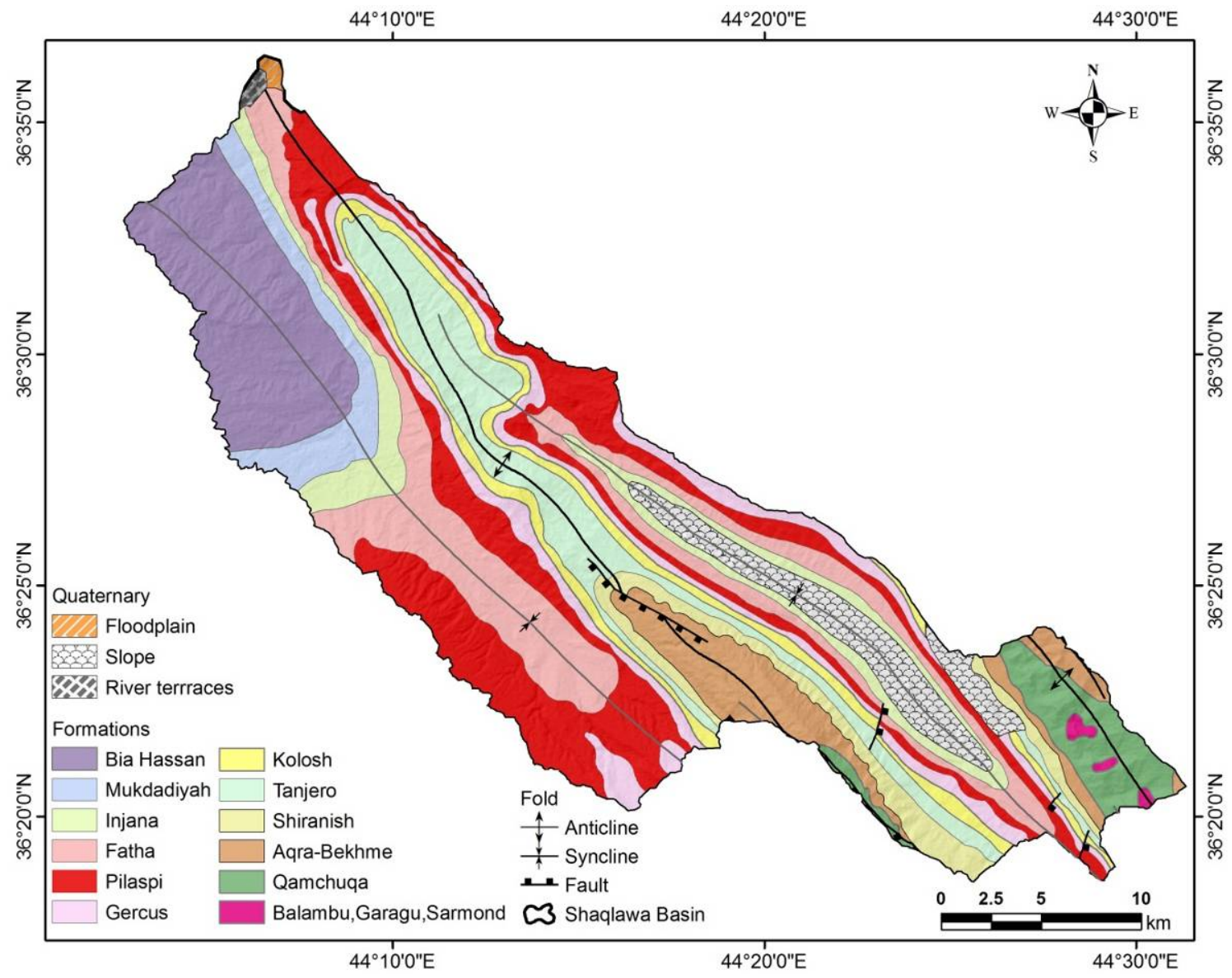

Figure 1B. Geological map of Shaqlawa basin 


\section{Appendix C}

\section{Supplement for the figures 6 and 7}
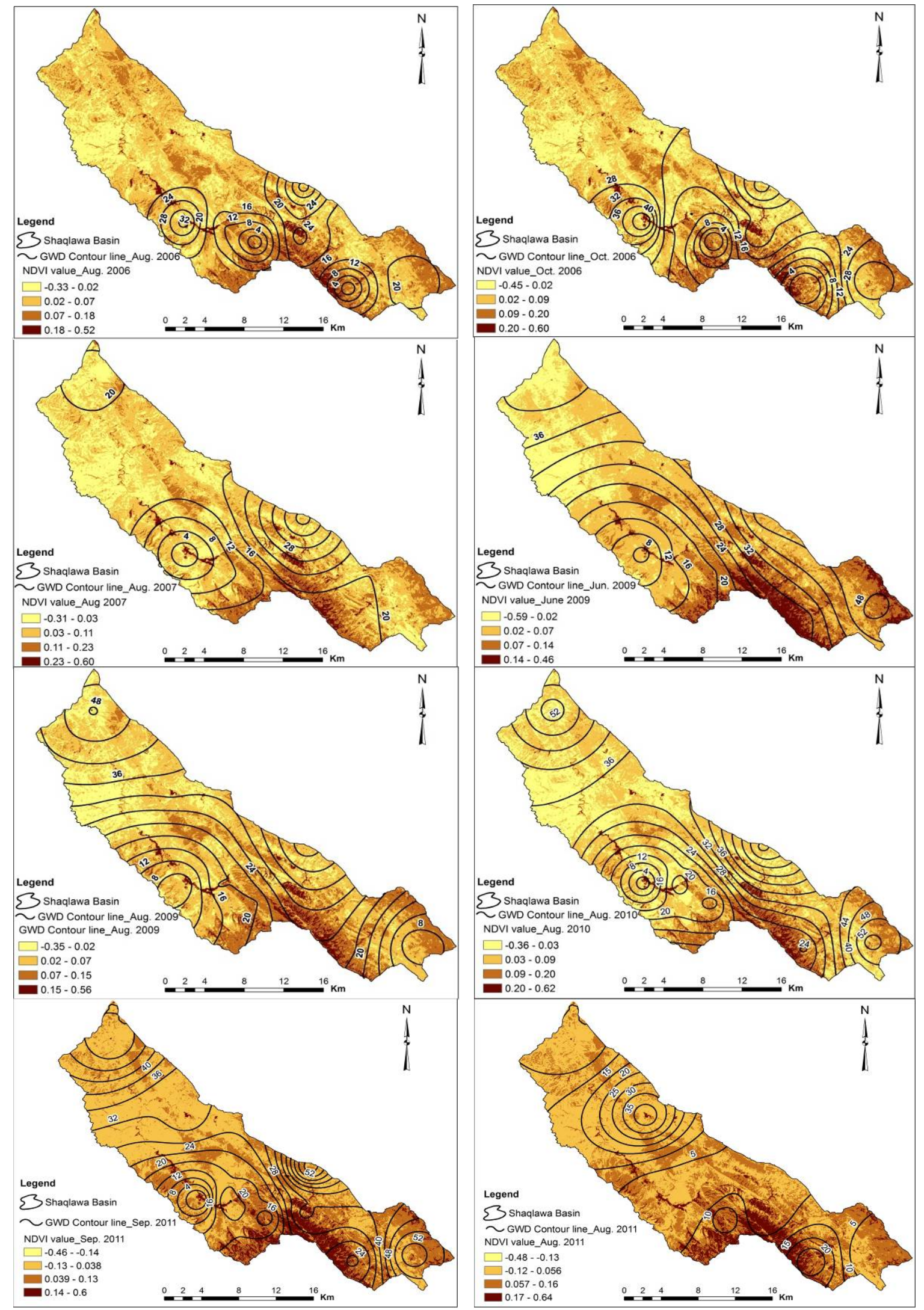

Figure 1C. Depths to groundwater contour lines with NDVI value for Shaqlawa basin during different periods, contour interval is 4 meter 

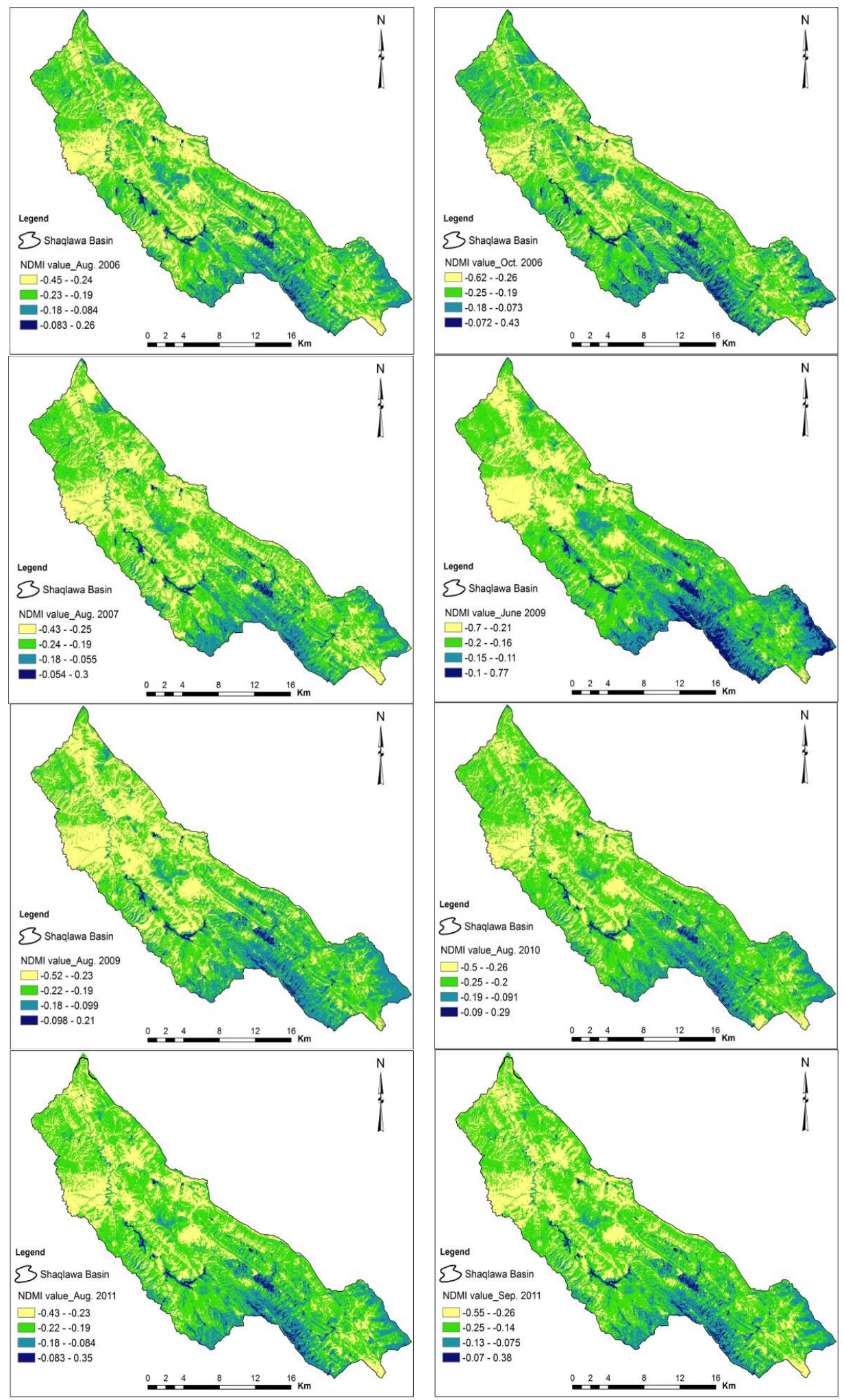

Figure 2C. NDMI values for Shaqlawa basin during different periods

\section{Copyrights}

Copyright for this article is retained by the author(s), with first publication rights granted to the journal.

This is an open-access article distributed under the terms and conditions of the Creative Commons Attribution license (http://creativecommons.org/licenses/by/3.0/). 